Dear Sir,

\section{Determination of Electron Affinity of Phenyl Radical by Dissociative Electron Attachment Technique}

Electron affinity is an important fundamental property of interest in different fields of chemistry. ${ }^{1,2}$ Among the various methods used for gas-phase electron affinity determinations, electron photodetachment, ${ }^{3,4}$ gas-phase ion-molecule equilibria measurements with a pulsed electron source and highpressure mass spectrometry, ${ }^{1,2}$ ion cyclotron resonance ${ }^{5,6}$ and flowing afterglow techniques ${ }^{6,7}$ are the most reliable. The dissociative electron attachment technique is a simpler alternative for electron affinity determinations.

Our previous attempts to use this technique for the determination of electron affinities of different radicals in the gas phase yielded higher values than published data obtained by other techniques. ${ }^{8,9}$ Specifically, the electron affinity of the phenyl radical, determined from the dissociative electron attachment processes of $\mathrm{C}_{6} \mathrm{H}_{5} \mathrm{COX}$, where $\mathrm{X}=\mathrm{CH}_{3}, \mathrm{H}, \mathrm{OH}$ and $\mathrm{Cl}$, yielded $2.4 \mathrm{eV}$, very close to an unpublished value of Gaines. ${ }^{10}$ In this paper, however, we report a similar determination of the electron affinity of the phenyl radical from the dissociative electron attachment to nitrobenzene which yields $1.2 \mathrm{eV}$, in very good agreement with a recently published value of $1.1 \mathrm{eV} .{ }^{11}$ The high electron affinity values obtained in our previous studies must now be attributed to the result of ionization processes from electronically excited states of the parent ion rather than the experimental limitations of the dissociative electron attachment technique.

The experimental set-up has been described previously. ${ }^{9}$ Basically, it consists of a 'trochoidal electron monochromator' (TEM) to produce a nearly monoenergetic electron beam and a quadrupole mass filter (QMF) to analyse the ions produced as a function of electron energy. The width of the electron energy distribution is determined as $0.2 \mathrm{eV}$ (FWHM) by measuring the ion yield curve of $\mathrm{SF}_{6}{ }^{-}$resulting from the electron attachment on $\mathbf{S F}_{6}$. Attempts to reduce the width of the electron beam caused a severe reduction in the ion yield and restricted further improvement. The ion formation chamber of the QMF is modified for time-of-flight measurements to determine the excess translational energy imparted to ions during the dissociation process, which can be used to calculate the total excess energy of the fragmentation process. ${ }^{12,13}$

Electron attachment to nitrobenzene in the range $0-10 \mathrm{eV}$ produced a strong molecular ion, $\left[\mathrm{C}_{6} \mathrm{H}_{5} \mathrm{NO}_{2}\right]^{-}$[appearance potential $(\mathrm{AP})=0.0 \mathrm{~V}]$, and fragment ions $\left[\mathrm{C}_{6} \mathrm{H}_{5} \mathrm{NO}\right]^{-}$ $(\mathrm{AP}=2.3 \mathrm{~V}),\left[\mathrm{C}_{6} \mathrm{H}_{5} \mathrm{O}\right]^{-}(\mathrm{AP}=3.3 \mathrm{~V}),\left[\mathrm{C}_{6} \mathrm{H}_{5}\right]^{-}(\mathrm{AP}=1.9$ $\mathrm{V}),\left[\mathrm{C}_{5} \mathrm{H}_{5}\right]^{-}(\mathrm{AP}=2.9 \mathrm{~V})$ and $\left[\mathrm{NO}_{2}\right]^{-}(\mathrm{AP}=0.8 \mathrm{~V})$. Figure 1 shows the ion yield curves of the ions relevant to this report, i.e. $\left[\mathrm{NO}_{2}\right]^{-},\left[\mathrm{C}_{6} \mathrm{H}_{5}\right]^{-}$and $\left[\mathrm{C}_{6} \mathrm{H}_{5} \mathrm{NO}_{2}\right]^{-}$. The electron attachment process giving rise to $\left[\mathrm{NO}_{2}\right]^{-}$and $\left[\mathrm{C}_{6} \mathrm{H}_{5}\right]^{-}$can be associated with the following reactions:

$$
\begin{aligned}
\mathrm{C}_{6} \mathrm{H}_{5} \mathrm{NO}_{2}+\mathrm{e}^{-} \rightarrow\left[\mathrm{C}_{6} \mathrm{H}_{5} \mathrm{NO}_{2}\right]^{-*} & \rightarrow\left[\mathrm{NO}_{2}\right]^{-}+\mathrm{C}_{6} \mathrm{H}_{5} \\
& \rightarrow\left[\mathrm{C}_{6} \mathrm{H}_{5}\right]^{-}+\mathrm{NO}_{2}
\end{aligned}
$$

The energy balance of the dissociative electron-capture processes yielding $\left[\mathrm{NO}_{2}\right]^{-}$and $\left[\mathrm{C}_{6} \mathrm{H}_{5}\right]^{-}$can be given as

$$
\begin{aligned}
& A E\left(\left[\mathrm{NO}_{2}\right]^{-}\right)=D E\left(\mathrm{C}_{6} \mathrm{H}_{5}-\mathrm{NO}_{2}\right)-E A\left(\mathrm{NO}_{2}\right)+E^{*} \\
& A E\left(\left[\mathrm{C}_{6} \mathrm{H}_{5}\right]^{-}\right)=D E\left(\mathrm{C}_{6} \mathrm{H}_{5}-\mathrm{NO}_{2}\right)-E A\left(\mathrm{C}_{6} \mathrm{H}_{5}\right)+E^{*}
\end{aligned}
$$

where $A E$ is the appearance energy, $D E$ is the bond dissociation energy, $E A$ is the electron affinity and $E^{*}$ is the excess energy.
Using the published bond dissociation energy of $\mathrm{C}_{6} \mathrm{H}_{5}-\mathrm{NO}_{2}$ of $3.1 \mathrm{eV}\left(298.3 \mathrm{~kJ} \mathrm{~mol}^{-1}\right)^{14}$ and approximating the excess energy term to be zero, the electron affinity of $\mathrm{NO}_{2}$ radical can be determined as $2.3 \mathrm{eV}$, in excellent agreement with the value determined by a wide variety of experimental techniques $(2.39 \mathrm{eV}$ from gas-phase electron transfer equilibria, ${ }^{2} 2.36 \mathrm{eV}$ from photodetachment ${ }^{15}$ and $2.11 \mathrm{eV}$ reported by Chen and Wentworth ${ }^{16}$ ). Similarly, we can now determine the electron affinity of the $\mathrm{C}_{6} \mathrm{H}_{5}$ radical as $1.2 \mathrm{eV}$, again in excellent agreement with the recently reported value of $1.1 \mathrm{eV} .^{11}$

We now return to our previous $E A$ determination of the phenyl radical from the series of molecules designated $\mathrm{C}_{6} \mathrm{H}_{5} \mathrm{COX}^{8}$ In substituted benzene molecules the lowest unoccupied molecular orbital (LUMO) energy is expected to be lowered either by introduction of electron-withdrawing substituents or by expansion of the $\pi$-conjugation. Both CXO and $\mathrm{NO}_{2}$ groups have a high electron-withdrawing power hence both stabilize the LUMO of benzene. However, the electron-withdrawing power of $\mathrm{NO}_{2}$ is considerably larger. Further, charge delocalization on the substituent is also larger for $\mathrm{NO}_{2}$. These effects together with the large dipole moment of the nitrobenzene molecule have been attributed to the long lifetime $(17.5 \mu \mathrm{s})$ of the parent molecular anion, ${ }^{17}$ indicating the existence of an unoccupied bound electronic orbital in the neutral molecule. Strong molecular anion formation in nitrobenzene is also evident from our experimental data, in sharp contrast to the case of $\mathrm{C}_{6} \mathrm{H}_{5} \mathrm{CXO}$ molecules where no parent ion could have been observed. It can therefore be concluded that the $\left[\mathrm{C}_{6} \mathrm{H}_{5}\right]^{-}$ions observed from $\mathrm{C}_{6} \mathrm{H}_{5} \mathrm{CXO}$ molecules are dissociation products of electronically excited parent ions

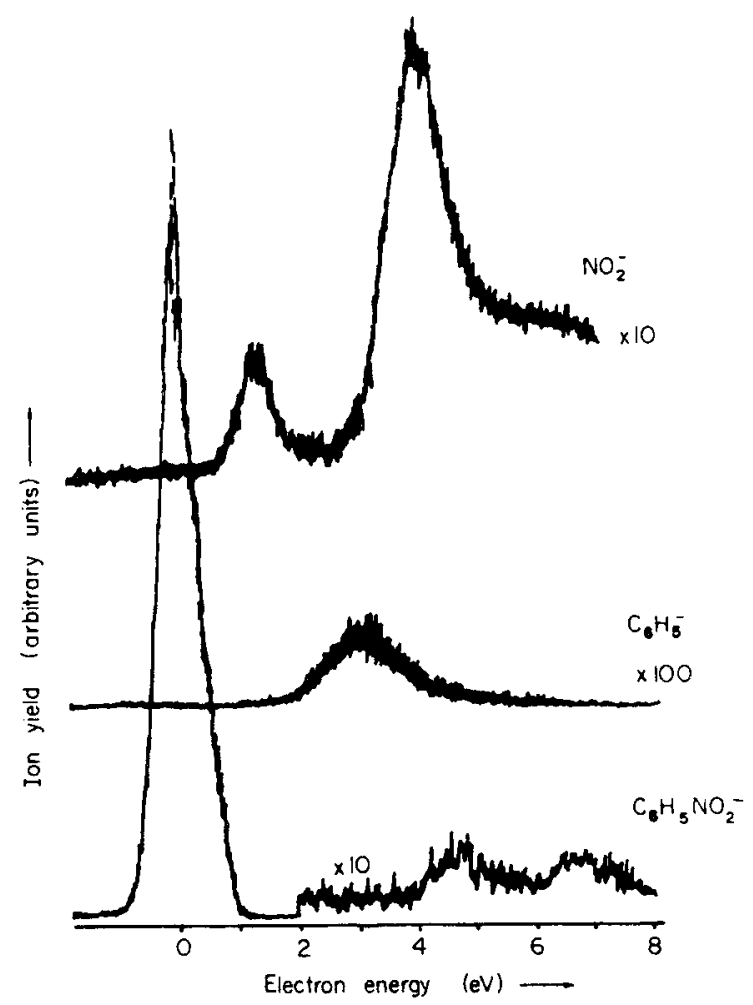

Figure 1. Ion yield curves of $\left[\mathrm{C}_{6} \mathrm{H}_{5} \mathrm{NO}_{2}\right]^{-},\left[\mathrm{C}_{6} \mathrm{H}_{5}\right]^{-}$and $\left[\mathrm{NO}_{2}\right]$ from $\mathrm{C}_{6} \mathrm{H}_{5} \mathrm{NO}_{2}$ 
in which the energy balance equation cannot be applied, whereas those from $\mathrm{C}_{6} \mathrm{H}_{5} \mathrm{NO}_{2}$ are produced from the ground state of the parent ion.

We acknowledge financial support provided by the Third World Academy of Sciences through research grant No. BC 91-037.

Yours

JALE HACALOGLU

Department of Chemistry,

Middle East Technical University,

06531 Ankara,

Turkey

\section{ALEC GAINES}

Department of Marine Sciences,

Middle East Technical University,

06531 Ankara,

Turkey

\section{SEFIK SUZER}

Department of Chemistry,

Bilkent University,

06533 Ankara,

Turkey

\section{References}

1. P. Kebarle and S. Chowdhury, Chem. Rev. 87, 513 (1987), and references cited therein

2. E. P. Grimsrud, G. Caldwell, S. Chowdhury and P. Kebarle, $J$. Am. Chem. Soc. 107, 4627 (1985)

3. R. D. Mead, A. E. Stevens and W. C. Lineberger, Gas Phase Ion Chem. 3, 214 (1984)

4. P. S. Drazaic, J. Marks and J. I. Brauman, Gas Phase Ion Chem. 3, 168 (1984).

5. M. T. Bowers, D. H. Aue, H. M. Webb and R. T. Mclver, J. Am. Chem. Soc. 93, 4314 (1971).

6. S. G. Lias, J. F. Liebman and R. D. Levin, J. Phys. Chem. Ref Data 13, 695 (1985)

7. A. W. Castleman and R. G. Keese, Chem. Rev. 86, 589 (1986).

8. J. Hacaloglu, A. Gokmen, S. Suzer, E. Illenberger and H. Baumgartel, J. Phys. Chem. 93, 7095 (1989).

9. J. Hacaloglu, A. Gokmen and S. Suzer, J. Phys. Chem. 93. 3418 (1989).

10. A. Gaines, unpublished results.

11. E. Illenberger, P. B. Comita, J. I. Brauman, P. Fenzlaff, H. Martin, N. Heinrick, W. Koch and G. Frenking, Ber. Bunsenges. Phys. Chem. 89, 1026 (1985)

12. E. Illenberg, Chem. Phys. Lett. 80, 153 (1981)

13. P. W. Harland, J. L. Franklin and D. E. Carter, J. Chem. Phys 58,1430 (1973).

14. C. C. Han and J. I. Brauman, J. Phys. Chem. 94, 3403 (1990).

15. E. Herbst, T. A. Patterson and W. C. Lineberger, J. Chem. Phys. 61, 1300 (1974)

16. E. C. Chen and W. E. Wentworth, J. Chem. Phys. 63, 3183 (1975).

17. W. T. Naff, R. N. Compton and C. D. Cooper, J. Chem. Phys. 54, $212(1971)$ 